\title{
Implementing Early Supported Discharge in Patients with Acute Exacerbation of Chronic Obstructive Pulmonary Disease
}

\author{
Sally Hickman MA BSc NMP RGN \\ Respiratory Nurse Specialist \\ South London Healthcare, Queen \\ Elizabeth Hospital \\ Stadium Rd, Woolwich, SE18 4QH \\ Phone Number: 02088364109 \\ Fax Number: 02088364090 \\ Email: sally.hickman@nhs.net
}

\author{
Dr Omorogieva Ojo PhD MSc PgDip BSc \\ RNutr. \\ Senior Lecturer in Primary Care, \\ Department of Acute and Continuing \\ Care, \\ School of Health and Social Care \\ University of Greenwich, Avery Hill \\ Campus \\ London. SE9 $2 U G$
}

\begin{abstract}
Aim: The purpose of this paper is to present the development and implementation of Early Supported Discharge (ESD) for those patients admitted to hospital with an acute exacerbation of chronic obstructive pulmonary disease (COPD). It also outlines the collaboration between secondary and primary care using Kotters 8-step change model.

Background: Acute exacerbation of chronic obstructive pulmonary disease (COPD) accounts for 1:20 emergency admissions daily, 500 of which are admitted spending an average of 6.5 days in hospital. Alternatives to managing exacerbation of COPD in a hospital setting were first suggested by the Royal College of Physicians in 1981. Emergency admissions for COPD place a significant burden on the resources of the NHS. Methods: Kotters 8-step model of change was used in this study. All adult patients (55 years or older) admitted to the Acute Medical ward with an exacerbation of COPD were assessed for their suitability for ESD. The period of the study was from February to June 2011. The service was operational from Monday to Thursday, and between the hours of 09.00 and 12 midday.

Patients admitted with the diagnosis of COPD were identified by;
\end{abstract}

- Accessing admissions information via a hospital information system

- Referral from nurse in charge of admissions ward

- Referral from Doctors.

Results: The approach adopting a change model has resulted in a period of six months 27 patients being discharged under the ESD scheme. Only one patient was readmitted within 30 days.

Conclusion: Approaching the change in smaller steps encourages reflection and development of leadership skills, and analysing the small steps allowed the development of a clear strategy which moved ESD forward. This service development has been a very positive experience, in the main due to the collaboration between the Respiratory Nurses and COPD Team.

Keywords: Early supported discharge, Chronic Obstructive Pulmonary Disease, Community, Primary care, Multidisciplinary team, Change management, Kotter's 8-step Model.

\section{INTRODUCTION}

The purpose of this paper is to present the outcomes of a study undertaken to develop and implement 'Early Supported Discharge' (ESD) in the management of Chronic Obstructive Pulmonary Disease (COPD) exacerbation in a District General Hospital, based on Kotter's eight-step model of change. It also involves outlining the role of the Respiratory Nurse, working in collaboration with another Respiratory Nurse Specialist and the community COPD team in the implementation of ESD scheme in COPD patients on acute emergency admission. Current evidence will be used to support the process of developing and implementing the ESD plan. The use of Kotters 8-step model assists health professional manage multiple time lines, create a vision for the organisation and build a coalition amongst healthcare professionals working as a team.

\section{BACKGROUND}

COPD Team Model

The COPD team under study was launched in 2006 and is a community based team. The team works collaboratively with two Respiratory Nurse Specialists who are based in the hospital. Developing and establishing a cooperative and collaborative working relationship leads to a strong working union. 
Working across boundaries reduces protectionist and demarcation of work, thus strengthening working relationship (Rushmer 2005). Teams such as this have invisible walls to negotiate, working under different management structures by virtue of either being employed by secondary or primary care. The aim of the COPD team has been to provide accurate diagnosis, management of exacerbations and pulmonary rehabilitation. The community team consists of Community Matrons, physiotherapists and support workers. Interprofessional collaboration has a positive impact on health care, as it involves negotiation between professionals, sharing of expertise all of which improves the patient's clinical outcomes (Zwarenstein et al 2009). Geographically, the team works from different locations; clinical discussions take place via the phone, contact is several times a day and meetings are held weekly in the form of a multidisciplinary team (MDT) meeting. The MDT meeting is held in the hospital which allows the team immediate access to clinical results and medical notes. Information sharing is necessary to ensure that the patients are managed appropriately and in line with the Department of Health (DH) Information Charter which outlines the standard that should be adhered to when dealing with information (DH 2010a\&b).

Alternatives to managing exacerbation of COPD in a hospital setting were first suggested by the Royal College of Physicians in 1981 (Ram et al 2009). Emergency admissions for COPD place a significant burden on the resources of the National Health Service (NHS). The Healthcare Commission (2006) in a national survey of COPD reported an increase in rates of emergency admission and readmission to hospital, 109,000 patients in $2000 / 2001$ increasing to 130,000 in 2004/2005. The median length of stay in 2008 was five days and readmission within 28 days of being discharged is increasing, $33 \%$ in 2008, up from $31 \%$ in 2003 (Department of Health 2010 a\&b). Furthermore the strategy highlights the continued high cost of care which is still predominantly delivered in secondary care. This cost is estimated to be between $£ 810$ million and $£ 930$ million a year (British Thoracic Society 2006). Therefore, alternatives to hospital admission have been explored and research has been undertaken to establish a criteria for which patients can be safely discharged early. "Hospital at home" and "early supported discharge" is the terminology used to describe this alternative management of patients exacerbating with COPD. National
Institute of Clinical Excellence ( NICE) (2010) wrote 'Hospital at home and assisted discharge schemes are safe and effective and should be used as an alternative way of caring for patients with exacerbations of COPD who would otherwise need to be admitted to hospital'. Patients and carers satisfaction with this type of care have been explored, and satisfaction is reported as high (Ojoo et al 2002). Early supported discharge schemes for the management of COPD exacerbations are considered a safe alternative to protracted hospital stays for about one in four COPD patients (Ram et al 2009).The NHS is helping more people live longer; however with rising costs of drugs and treatments, the current NHS cannot sustain the spending (Lansley 2011). Alternative methods of delivering patient care should be sought which results in patients having greater choice.

The Hospital under study serves a local population of 214,403 people (www.londoncouncils.gov.uk/services/lept/bor oughmap/greenwich). Acute exacerbation of chronic obstructive pulmonary disease (COPD) accounts for 1:20 emergency admissions daily, with an average length of stay of 6.5 days (NHS Greenwich 2010a).

Early Supported Discharge

The Strategy for COPD (DH 2010) recommended that patients should receive specialist respiratory review during acute episodes which require admission and this should be a structured approach offering ESD to minimise length of stay. NICE (2010) recommend all patients be considered for assisted-discharge schemes, providing resources are available and factors associated with worse prognosis are absent. Patients have been expected to fit around services, rather than services around them (DH $2010 \mathrm{a \& b}$ ). Offering ESD as an alternative model of care offers choice to our patients. The NHS is changing rapidly and the vision for the future is less confined to hospitals. Moving care to the community will transfer the cost from secondary care to the community. Wells (2009) in a published report on hospital care at home presented commissioners and providers with the financial analysis of such a service, which demonstrated cost savings and improvements in patient outcomes and experiences. Ram et al (2009) reviewed 7 randomised controlled studies. Two studies included cost analysis and implementing hospital at home equated to overall cost saving of approximately $£ 540$ per patient. Cotton et al (2000) and Skwarska et al (2000) published the findings of their randomised studies which explored the introduction of ESD in acute 
hospital settings. The results of these two studies concluded that ESD was a safe alternative to hospital management in a small number of patients. The British Thoracic Society (2006) published a review of the literature and this document outlines best practice for ESD.

Having reflected on the process, some questions relating to the drive for ESD readily come to mind. Could it be due to;

- Economic gain?

- Patient satisfaction?

- Quality of care?

Overview of the study

This study implemented the ESD by using Kotters 8- Step model. Having an insight and understanding of the theories of change allows managers to predict what the possible implications and reactions might be, before attempting to implement organizational change (McPhail 1997). Change is not linear, it is complex and multiple time lines require management. It is the balancing of the shortterm results with long-term vision which results in high probability of sustained success (Kotter 1998).

As the purpose of this study was to use a change model to implement ESD, the Kotters 8 - Step model is briefly outlined below;

- Establishing a sense of urgency

- Form a powerful guiding coalition
- Creating a sense of vision

- Communicating the vision

- Empowering others to act on the vision

- Planning and creating short-term wins

- Consolidating improvements and producing still more change

- Institutionalizing new approaches

\section{METHOD}

All adult patients, 55 years or older who were admitted to the Acute Medical ward with an exacerbation of COPD were assessed for their suitability for ESD. For the study period of February to June 2011, 27 patients were discharged from hospital on the ESD scheme, out of a potential 295 acutely admitted with exacerbation of COPD. The service was operational from Monday to Thursday, and between the hours of 09.00 and 12 midday.

Patients admitted with the diagnosis of COPD were identified by;

- Accessing admissions information via a hospital information system

- Referral from nurse in charge of admissions ward

- Referral from Doctors.

Once referral was received the patient was seen by the respiratory nurse and a clinical assessment undertaken- as outlined in Box A.

\section{Box A}

- Blood pressure, heart rate, respiratory rate, temperature, pulse oximetry

- Inhaled and oral medication

- Spirometry to confirm diagnosis of COPD

- Assessment of activities of daily living

- Social situation, telephone access and carers.

The British Thoracic Society identified indicators which may potentially predict relapse in patients with acute exacerbation of
COPD. This was written as exclusion criteria for ESD and this criterion was used when reviewing the patients in this study, as outlined in Box B (British Thoracic Society 2006).

\section{Box $B$}

- Impaired level of consciousness

- $p H<7.35$

- Acute changes on chest radiograph

- Concomitant medical problem requiring inpatient stay

- Insufficient social support

- No telephone

- Patient outside geographical boundaries of COPD team 
Once this patient was assessed as suitable for discharge then discharge arrangements were made as outlined in Box $\mathrm{C}$.

\section{Box $C$}

- Medications prescribed for discharge on To Take Out form, a copy given to the patients and copy faxed to General Practitioner (GP).

- Patient receive bedside education re use of oral and inhaled medication:correct inhaler technique, potential side effects of oral and inhaled drugs.

- $\quad$ Time of next visit from COPD team and contact details of team provided. Written information outlining ESD given to patient.

- $\quad$ ESD referral form completed by the Respiratory Nurse outlining clinical findings faxing the copy to COPD Team and GP.

Patient records are updated and data are collated. Each patient discharged under ESD scheme would receive a plan of care, outlined in Box D

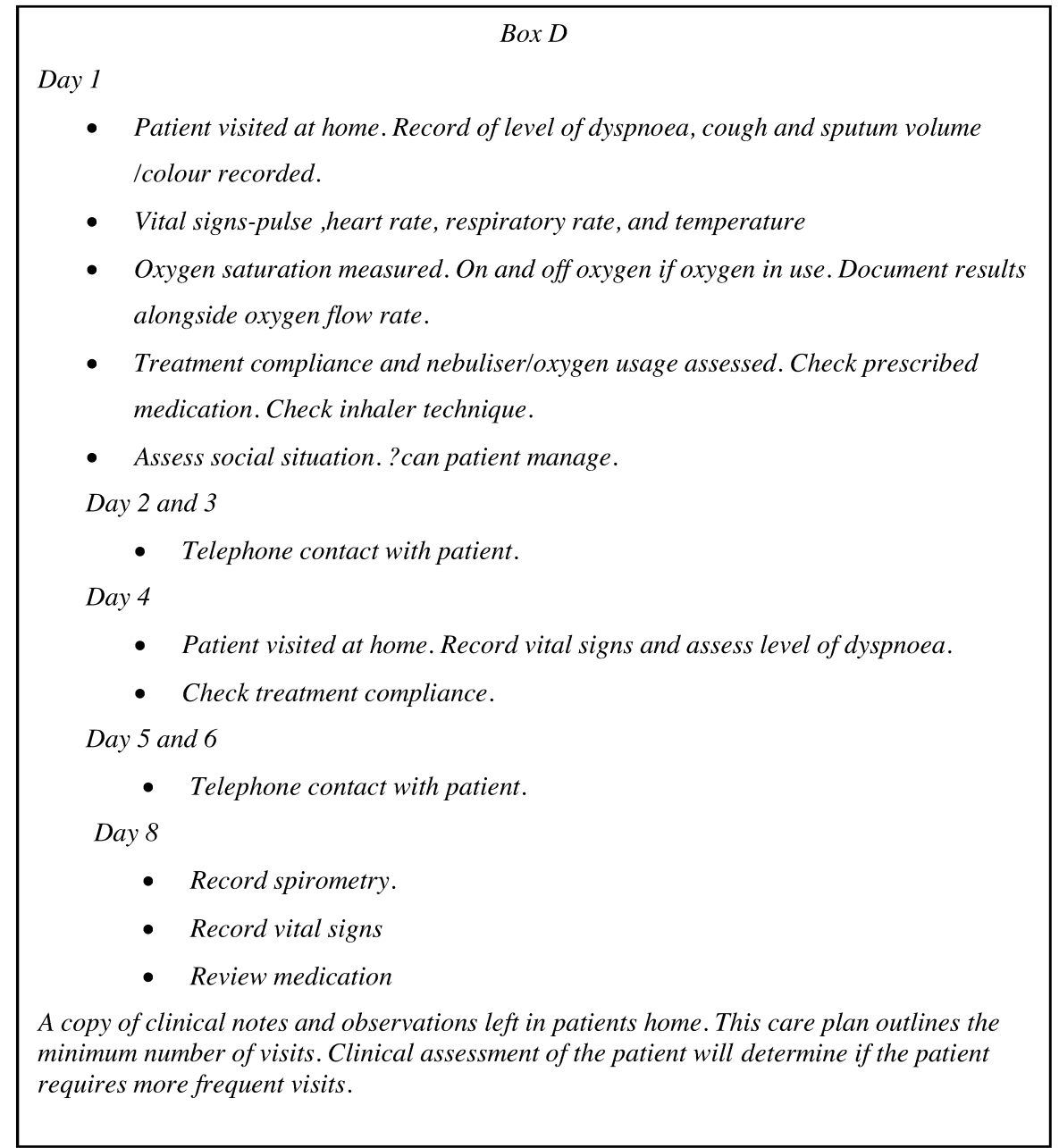




\section{APPLICATION OF KOTTER 8-STEP MODEL AND IMPLICATIONS FOR PRACTICE}

Step 1: Establish a sense of urgency

With COPD costing $£ 800$ million to the NHS and one million in-patient bed days every year alternatives to protracted hospital care need to be sought (Chief Medical Officer - CMO 2004). Previously, a model of change had not been adopted to support and implement the vision for ESD. The trust had employed a new Chest Physician to provide clinical lead for the COPD team, and a new Acute Physician with a Respiratory interest. Kotter (1996) describes the need to empower a broad base of people. If enough people in the organisation understand the potential gains then they will embark on the change. The Healthcare Commission (2006) highlighted the need for primary care trusts (PCTs) and the NHS in general to improve COPD diagnosis, develop care appropriate to patients' needs and reduce the number of patients admitted to hospital. The service model for the COPD team were based on;

- Partnership working with all healthcare professionals

- Coordination and management of exacerbation: facilitating discharge to reduce length of stay

- Pulmonary rehabilitation

- Integrated oxygen service

- End of life referral and support

A review of these objectives highlighted the urgency in developing ESD. Patients access health care from a number of different routes, which is essential as they may have complex needs. People with long term conditions consistently say that they do not want to be in hospital (DH 2010 a\&b), while teams managing long term conditions case manage, personalise care and support patients to self manage (DH 2010 a\&b). Identifying the correct patient for ESD is essential for its success. It was reported by the Greenwich Commissioners (NHS Greenwich 2010b) in their annual report that 591 patients were admitted with exacerbation of COPD in 2009/10. Attempts have been made to establish the nature of exacerbation. Burge and Wedzicha (2003) describe an exacerbation of COPD as a sustained worsening of the patient's condition, from the stable state and beyond normal day-to-day variations that is acute onset and may warrant additional treatment. Reducing length of stay is the primary outcome of ESD; readmission rate was identified as a primary outcome measure in the studies published. Ram et al (2009) evaluated 7 studies in which comparisons of readmission rate between usual discharge or ESD. The study found the readmission rate was not different in each arm. Therefore the COPD team had the capacity within the service to develop ESD and the relevant supporting literature did not identify a greater risk of readmission in those patients correctly selected.

Ram et al (2009) identified the importance of chest x-ray, arterial blood gases and clinical assessment before patients could be assessed for their suitability for ESD. What is not measurable is the patient's perception of their breathlessness, it is the increased level of breathlessness which is extremely difficult to quantify resulting in significantly reduced exercise.

ESD services are run collaboratively, therefore understanding the patients symptoms beyond those that which are measurable is important for its success. The success of the vision hinged on the working relationship between all professionals. Creating a culture which emphasizes group affiliation, teamwork, and coordination are associated with greater implementation of improved quality and change (Scott et al 2003). Kotter (1996) emphasises step 1 as a renewal process requiring strong leadership, creating urgency is the powerful catalyst to move services forward. A convincing argument is essential when addressing the audience who are to be pivotal in the service change. With the appointment of a new Chest Physician and Acute Admitting Physician, an excellent opportunity to emphasize group affiliation and team work arose. Acute medicine is a new speciality, born out of identified delays in assessment, poor outcomes and many people staying in hospital longer than necessary (Langlands et al 2008). For the role of Acute Physician to be successful, teamwork and strong, well-defined and consistent clinical leadership are essential. The agenda in the hospital under study is to ensure that patients admitted are discharged at the earliest possible opportunity. All patients admitted are transferred from A\&E to the acute admissions ward and are seen by a Consultant on call within a few hours of admission.

Each preceding day the respiratory patients are identified and put under the care of the Acute Physician with a respiratory interest. Ideally what should follow is collaborative working with the Chest Physician and appropriate 
identification of patients who will require a protracted length of stay ie longer than 3 days. Respect for each other and their skills are essential if teams are to work collaboratively and across professional boundaries. In addition, the urgency rate has to reach $75 \%$ in those professionals involved in the change; otherwise it is business as usual (Kotter 1995).

Step 2: Forming a powerful guiding coalition High-quality performance is more likely to take place in a setting where the climate is positive and those individuals working as part of a team are open to change. The COPD team had formed a powerful coalition, working across secondary and primary care, largely due to a common case load of patients. Coalition building is not simply reaching out to who ever happen to be in charge, but it is assembling the right professionals with the talent and skills to move the vision forward (Kotter 1998). The approach to building the powerful guiding coalition for ESD is outlined in Box 1.

Box 1: Forming a guiding coalition, creating a vision and communicating the vision

Planned meeting: 2 Chest Physicians, Acute Physician, Specialist Registrars, COPD Team lead and Respiratory Nurse were invited. The meeting was chaired by the Respiratory Nurse Specialist; minutes were taken for dissemination following the meeting. The ESD service vision was communicated to the assembled group.

Outcome of meeting:

- ESD would be offered Monday to Thursday 09.00hrs to 12 midday. Thus enabling patients to be discharged by early afternoon.

- Protocol outlining the proposed clinical input patients would receive following discharge is provided by the COPD Team lead.

The Consultants felt they could review patients daily alongside the Respiratory Nurse. It was anticipated that up to two patients a week would be suitable for ESD.

- When discussing cascading the vision, the Acute Physician offered to disseminate the information to all Acute Physicians. Communicating the vision to the Acute Physician by an Acute Physician is a positive outcome.

"I see them all and all the respiratory patients are under my care, so I will tell them all"

The meeting concluded and objectives were set and understood by all members of the group. The minutes were to be circulated.

Objectives set:

- Monday -Thursday 09.00-12.00 the designated Consultant would meet with the Respiratory Nurse and discuss any patients identified for discharge.

- Respiratory Nurse would keep accurate records of those patients discharge to allow for audit.

- Circulate clinical protocol for early supported discharge.

- Communicate the vision to all colleagues on admissions ward and respiratory ward.

- Acute Physician would speak directly to her immediate colleagues. 
Meetings are the springboard for ideas, it gives professionals the opportunity to explore information and formulate plan. Through increased collaboration, nurses and other professionals within the organisation share knowledge which can be utilized to facilitate goals (Sieloff 20004). Selling the vision is done by sharing with the group all known information surrounding the changing situation so the decision to proceed becomes a shared decision (Grohar-Murray and Langan 2011). Critchley (2007) describes the need for defined objectives, which are articulated clearly, and understood by all members of staff, regardless of role. This way all at the meeting understand the part they are to play.

Although personal problems often lurk beneath the surface of a team, undertaking clinical work together, sharing the vision and commitment ultimately moves the change forward (Kotter 1998). Following reflection on the response and consideration of various view points in the overall management of COPD patients, it was clear that a member's position was initially different from that of the team. Time potentially can be spent on trying to win support from individuals whose positions outweigh group interests (Grohar-Murray and Langan (2011). Working in a group to steer a service requires strong leadership and it is critical to ensure that the role of one member of the steering group does not impact negatively on the future success of ESD. In order to ensure the best clinical outcome for our patients, collaborative working has to be upper most in our working relationship.

Step 3: Create a vision

The strategy for achieving the vision has to be created. A vision says something that helps clarify the direction in which the organisation needs to move (Kotter 1995). While the vision created in the current study are outlined in Box 1 , the number likely to meet the criteria for ESD were up to two patients a week (Ram et al 2009). It is also useful to note that change is better accepted if a clear and consistent vision is communicated and without this, there is a potential to undermine the process (Narine and Persaud 2003). It isn't possible to predict the number of patients who would be admitted with exacerbation of COPD and those who would be suitable for ESD. Facilitating discharge in the morning allowed for follow up by the respiratory teams in the afternoon if clinically indicated (Cotton et al 2000). The larger of the trials offered a service which ran over seven days and patients were escorted home from A\&E by the respiratory nurse, which was known as 'Hospital at Home' (Davies et al 2000). It was not the intention to offer this level of service and this was not the vision which was to be shared.

The vision needed to be communicated not only to the nurse in charge but to all the acute physicians and pharmacists. Kotter (1995) talks of the vision needing to be easy to communicate, not buried in a lengthy explanation. If the vision cannot be communicated in five minutes then the transformation process is not complete (Kotter 1995).

There was a need to ensure that those senior nurses and Consultants understood the value of ESD and they bought into the vision.

Step 4: Communicate the vision

Communicating the vision beyond the steering group requires time investment although time investment may be difficult to quantify. It is also clear that a single meeting between the steering group will not drive the vision forward (Kotter 1995). Communication is a two way process of sending and receiving information, involving a complex exchange of thoughts, ideas or information on two levels: verbal and nonverbal (Chitty, 2001, cited in Marquis and Huston, 2003, p, 336). Marquis and Huston (2003) describe internal and external climates which exist and affect our communication. Our personalities, values, feelings and temperament, alongside status, power and organisational pressures create the complex path of communication. The message which is to be conveyed has to be understood firstly by the steering group which allows the vision to be disseminated to the larger audience (Box 1). In delivering the message, it was not only in words that the vision was conveyed but in non verbal behaviour. A combination of verbal and nonverbal behaviour can alter the tone of the message (Grohar-Murray and Langan 2011). Good communication builds relationships in the steering group and results in strengthening the leader's potential to lead. It is essential for the vision to be communicated that all members of the steering group are involved not by virtue of seniority but with a desire to contribute fully to the service change.

Leadership requires the skill of delegation and confidence in the members that they will take forward the ideas and vision from the steering group. The leader empowers the steering group to use every opportunity to utilise every possible channel to communicate the vision 
(Kotter 1995). If there are specific lines of communication to pursue then it would be appropriate to identify members of the steering group to undertake a particular task. It is essential not to assume that following a meeting all members of the group will remain focused.

As the lead on this project, the author understands that the role is to develop a cohesive team to meet the end point of a successfully integrated ESD service. As far as patients are concerned, services are delivered by professionals working collaboratively (Rushmer 2005).

The desired outcome of the group meeting was to ensure that the Senior Nurses and all Acute Consultants understood the limitations of the service. The Senior Nurses engaged with the ESD concept and understood that they had a pivotal part to play. Each morning a meeting was held to discuss discharges and potential moves of patients and this was held at the nurse's station, Doctors, nurses and allied health professionals attending.

Step 5: Empower others to act on the vision Empower means to enable, develop, or allow (Marquis and Hudson 2003). Leadership which communicates the vision leads to empowerment of staff, allowing them to flourish, developing their skills and making the most of their talents. It is important to tap into the passion of the staff; by ensuring that the staff understand the vision, which means understanding where a service like ESD fits clinically for COPD patients (Kotter 1998). Differentiating between information and knowledge is important. Information is data put into context. For example, if it is reported that a patient has a respiratory rate of 29 , the figure alone without clinical information is meaningless. However if the narrative, this is a patient with COPD who is distressed is added, this is now an information. Knowledge is capacity to reason and make sense of the information (Davenport and Prusack 1998 cited in Chaboyer and Blake 2008). The staff needed to be equipped with the skill of transferring knowledge and not just information. Understanding the vision gives them part of the information and providing clinical knowledge and reflecting on patients they have cared for begins to make it real. The steering group had the responsibility to take every opportunity to disseminate knowledge which will empower the staff. The trust offers an accredited "Introduction to Respiratory Nursing" course, which is facilitated by the Respiratory Nurse Specialist.

The focus is to develop the knowledge of the trained staff.

If there is an expectation to identify patients suitable for ESD then nurses managing patients clinically will require a sound knowledge of COPD. Studies on ESD described working with ward staff and generic medical teams, visiting the wards and discussing the patients each day (Cotton et al 2000). Undertaking courses begin the process of learning. A wide variety of methods for disseminating the vision is required. Formal teaching as described above is a useful approach while opportunities should be taken during each daily interaction to empower others to act on the vision. Formal teaching allows a larger audience where a consistent message will be delivered (Box 2). These initiatives were undertaken by the respiratory nurse whom the clinical teams are familiar with and recognise the experience and expertise of this professional. Resistance to change can come from individuals because of lack of knowledge and anxiety that the change may bring to the work place which in turn increases the work load (Glenn 2010) (Box 2).

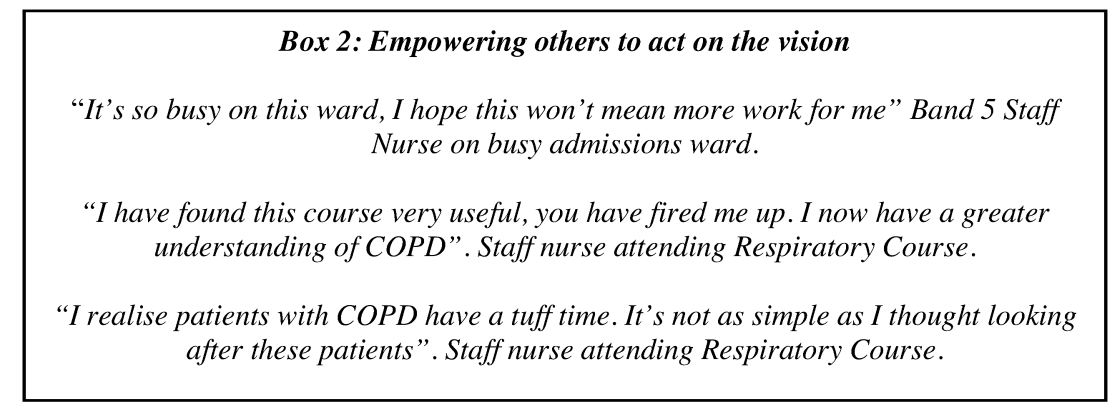

It is important to develop nurses to be confident practitioners. Interprofessional working aims to develop staff to be confident with strong core skills and they in turn will 
have confidence in the health professionals they work with (Cornes 2011). There is a great deal of knowledge around in many forms, be that policies, procedures, research and colleagues imparting their knowledge. In addition, there are many opportunities to update knowledge and skills such as through interactions on the wards:- including discussing ESD each morning with the nurse in charge of the admissions ward and with the Staff nurse caring for the patient. Regular weekly hour long teaching sessions took place to discuss COPD as a disease process and ESD. According to NMC (2008) "You must be willing to share your skills and experience for the benefit of your colleagues".

Step 6: Plan for and create short-term wins In any change process it is essential that celebrating the success is not premature. When
ESD was initially introduced the team considered it a success. Kotter (1998) encourages celebration of positive results, however points out the potential difficulties in declaring success too early. The COPD team need to know that their efforts were recognised. However, it is important that early rewards do not lead to complacency. Each month's data was collated, patients demographics, disease severity and length of stay. Goal setting at the beginning of the process allowed feedback to determine goal achievement (Narine and Persaud, 2003). The goal was to facilitate 2 patients a week onto ESD. One in four patients was considered suitable for ESD (Ram et al 2009). Understanding what patients want encourage the continued development of ESD.

\section{Box 3: Planning for and creating short term wins \\ "I know you are trying your best, but I want to go home as early as possible". ESD patient known to the team. \\ "The COPD team are really good and I know if I call them they will always come and see me". ESD patient known to the team. \\ "So the nurses will visit me at home. That's a great idea and I can get home, which is where I'd like to be". ESD referred to the team as a new patient.}

Words can be very powerful and provide an insight into the depth of

feeling. If the participants were to only consider the success of ESD based on up to 2 ESD a week, then the steering group may think the wins are small. However, it becomes evident when participants discuss with patients that every ESD is a success and needs to be replicated (Box 3).

Therefore, the short-term wins were achieving the 2 discharges a week and with the continued development of the ESD so financial benefits are seen. Feedback is in the form of weekly meetings between all members of the COPD team and Consultant. Monthly meetings for the ESD steering group, the education sessions on the wards allowed feedback on the short-term wins. Giving examples of improved performance is linked then to new ways of doing things (Narine and Persaud 2003). Feedback of intermediate goals keeps staff informed and ensures they see the success and they will continue to buy into the vision.

Step 7: Consolidate improvements and produce still more change
Acute admissions due to exacerbations of COPD in 2007/8 reached 260,000 episodes (DH $2010 \mathrm{a} \& \mathrm{~b}$ ). For the study period of February to June 2011, 27 patients were discharged from hospital on the ESD scheme, out of a potential 295 acutely admitted with exacerbation of COPD. The development of ESD has been in line with NICE (2010) recommendation that assisted-discharge schemes should be offered to selected patients. In any change process there are short-term and long-term aims. The leader alongside the ESD steering group has to balance these when considering the success of the vision. Kotter (1998) describes short-term as six months. Similar schemes have reported discharges of one to two patients a week (Cotton et al 2000, Davies et al 2000, Skwarska 2000). These studies took place over eighteen months. At all times commitment to produce the short-term wins and communicate them through feedback will keep the urgency level high (Narine and Persaud 2003). Therefore regular teaching sessions must continue to be provided to ensure continued exposure to the vision and clinical expertise of the steering group. When 
staff becomes preoccupied with the day to day tasks they soon lose interest in the service to be developed. value in the clinical setting and that staffs who have attended can share their positive findings (Box 4).

Feedback from the "Introduction to Respiratory Nursing" course highlights its

$$
\begin{aligned}
& \text { Box 4: Consolidating improvements and producing still more change } \\
& \text { Sister on acute medical ward } \\
& \text { "I will ensure all my Staff will apply for this course. I was lucky enough to } \\
& \text { spend a day with the COPD team in the community, we saw a patient who I } \\
& \text { have nursed in the hospital" } \\
& \text { Senior Staff Nurse } \\
& \text { "I spent the day with the COPD Team. We went to see a patient who had been } \\
& \text { discharged from my ward on ESD. She didn't recognise me but she said she } \\
& \text { was so glad to get home and the team were really helpful". }
\end{aligned}
$$

The feedback needs to be tailored to the audience, with the information which is necessary for the change process to proceed (Hutton 1997 cited in Narine and Persaud 2003). The "Introduction to Respiratory Nursing" course will include the research findings supporting ESD and the data from this study. Effective visions are focused enough to guide the change, but flexible enough to accommodate individuals (Kotter 1998).

Step 8: Institutionalize new approaches Institutionalising change into the organisation is the ultimate goal. Change is not a simple, linear process and improving the experience of users, patients and families is multi-factorial (Audit Commission 2001). There have been a number of improvements as a result of the introduction of ESD, including;

- Reduced length of stay

- Increased patient satisfaction

- Collaborative working

- Improved knowledge

It is important to know if the change has been successful and by performing an evaluation allows continued development of ESD. Ongoing monitoring for continued quality provides valuable information about the ongoing effectiveness of ESD. According to Grohar-Murray and Langam (2011), follow up findings allow analysis and replication of the success and correction of errors. To ensure ESD is institutionalised, it will continue to be on the agenda for the 'Introduction to Respiratory Nursing 'course. It would be wrong to imagine that at six months ESD is embedded in the organisation. The Trust is recruiting into vacant posts and those staff will need to be brought into the vision.
Auditing the process of ESD will allow the steering group to identify the changes required to ensure sustenance of the gains.

\section{CONCLUSION}

This paper has illustrated a service development which has been successfully implemented using the Kotter's 8-step model of change. As a result of undertaking this project, leadership skills and negotiation skills in colleagues who had been resistant to the change has developed and this ultimately has fostered a sense of confidence which empowered the project lead. Taking the opportunity to teach junior members of the teams who deliver the day to day care results in professional practice being influenced. The choice of model to guide the change is pivotal to the success. Kotter isn't prescriptive in the time allotted for each step and it seems reasonable that some steps will require a greater time investment. Previously in an attempt to introduce ESD, insufficient time was allotted to the guiding coalition.

That initial success led to early congratulations, which is important to recognise, but overall the ground gained was lost. The approach of adopting

a change model has resulted in 27 patients being discharged under the ESD scheme over a period of six months. Only one patient amongst the 27 patients was readmitted within 30 days. It is interesting that Kotter describes short term as six to twelve months. As the literature demonstrated up to two patients a week is a realistic outcome for ESD, therefore analysing the success too early potentially lead to criticism as the numbers may be 
perceived as too small. The 8-steps of Kotter allowed management of the complex communication and struggles in relation to the hierarchy within the guiding coalition.

\section{RECOMMENDATIONS}

- The Trust is an amalgamation of three district general hospitals, two of which provide acute care, therefore, replication of ESD in all the hospitals will need to be explored in the near future.

- The second acute Hospital in the Trust currently does not employ a Respiratory Nurse although there is a Respiratory Team serving their local population, therefore, there will be a need to have a Respiratory Nurse who should serve as a leader at the other acute hospital.

\section{REFERENCES}

[1] Audit Commission. (2001). Change here! Managing change to improve local services. London. Holbrooks LTD

[2] British Thoracic Society Guideline (2006) 'Intermediate care-Hospital-at-Home in chronic obstructive pulmonary disease'. Thorax: $200-$ 210

[3] Burge,S. Wedizicha, J. (2003) 'COPD exacerbations: definitions and classifications'. European Respiratory Journal 41, pp. 46-53

[4] Cornes, M (2011). The Challenge of Managing Change: What can we do differently to ensure personalisation. Journal of Integrated Care. 19(2): pp 22-29

[5] Cotton, M. Bucknall, C. Dagg, K. Johnson, M Macgregor, G. Stewart, C. and Steveson, R. (2000) 'Early discharge for patients with exacerbations of chronic obstructive pulmonary disease: a randomised controlled trial'. Thorax, 55, pp. 902-905.

[6] Critchley, D. (2007) 'The importance of good team work' Nursing Management, 14(7), pp. 812

[7] Chaboyer, W. and Blake, S. (2008). 'Information sharing, knowledge transfer and patient safety'. British Association of Critical Care Nursing. 13(3): pp 121-123

[8] Chief Medical Officer (2004) On the state of the public. Annual report of the Chief medical Officer. [ONLINE]. Available at: http//www dh gov.uk/en/Publicationsansstatisti cs/Publications/AmmalReports/DH 4115776 (Accessed: 1 July 2011).

[9] Davies, L. Wilkinson, M. Bonner, S. Calverley, P. and Angus, R. (2000) "Hospital at home" versus hospital care in patients with exacerbations of chronic obstructive pulmonary disease: prospective randomised controlled trial. British Medical Journal. 321,1265-1268.
[10] Department of Health (2010a) Consultation on a Strategy for Services for Chronic Obstructive Pulmonary Disease (COPD) in England. London

[11] Department of Health (2010b) Information Charter. [ONLINE]. Available at: htp//www dh gov.uk/en/Freedomontnformatio W/DH 088010 (Accessed: 1 July 2011).

[12] Grohar-Murray, M. and Langan, J. (2011) Leadership and management in Nursing. $4^{\text {th }}$ edn. USA: PearsonGlenn, L. (2010) 'Implementing change'. Journal of Community Nursing. 24(5): pp 10-14.

[13] Healthcare Commission (2006) Inspecting Informing Improving. Improving healthcare for patients through annual health check. [Online]. Available at: http//www official. documents gov uk/documentho0607 (accessed: 6 January 2011)

[14] Kotter, J. (1995) 'Why transformation efforts fail'. Harvard Business Review. pp 59-67

[15] Kotter, J. (1996). Leading change. $1^{\text {st }}$ edn. United States of America: Harvard Business Review Press

[16] Kotter, J. (1998). Winning at change. [Online]. Available htp//www providersedge com/ehdocs/ransfor
her mation articles/WINNING AT CHANGE.pd (Accessed 28 June 2010).

[17] Lansley, A. (2011) 'Why the health service needs surgery' Telegraph, 1 June 2011 [Online]. Available at : http:/ www telegraph co uk/commentpersonal. view/8551239 (Accessed: 5 June 2011).

[18] Langlands, A. Dowdle, R. Elliott, A. Gaddie, J. Graham, A. Johnson, G. Lam, S. McGowan, A. McNamee, P. Morrison, J. Murphy, T. Reynard, K. Rudge, P. and Trueland, J. RCPE UK Consensus statement on acute medicine November 2008. [Online]. Available at: http//www repe ac uk/clinical-standards/finalstatement-rope-consensus-conferenec-on-acutemedicine-noy-2008 (Accessed: 12 June 2011).

[19] Marquis, B. and Huston, C. (2003) Leadership roles and management functions in nursing. Theory and application. $4^{\text {th }}$ edn. USA. Lippincott

[20] McPhil, G. (1997). ,Management of change: an essential skill for nursing in the 1990s'. Journal of Nursing Management. 5, pp199-205

[21] NHS Greenwich (2010b) Module BPerformance requirements- Specification, Quality and Productivity Greenwich Community Health Services October 2010.

[22] Narine, L. and Persaud, D. (2003). 'Gaining and maintaining commitment to large-scale change in healthcare organizations'. Health Service Management Research. 16, pp 179-187.

[23] National Institute for Clinical Excellence ( 2010). Guideline 12 Management of Chronic obstructive pulmonary disease in adults in 
primary and secondary care. London: National Institute for Clinical Excellence.

[24] NHS Greenwich (2010a) Chronic Obstructive Pulmonary Disease (COPD) Care Pathway. Greenwich Community Health Services. 18 October 2010.

[25] Nursing and Midwifery Council (2008) Code of Professional Conduct. [Online]. Available at: htto://ww mme-uk org/Nurses-andmidwives The-code-infull. (Accessed 3 July 2011).

[26] Ojoo, J. Moon, T. McGlone, S. Martin, K. Gardiner, E. Greenstone, M. and Morice, A. (2002) 'Patients' and carers' preferences in two models of care for acute exacerbations of COPD: results of a randomised controlled trial'. Thorax. 57: 167-169

[27] Rushmer, R. (2005) 'Blurred boundaries damage inter-professional working', Nurse Researcher; 12 (3), pp. 74-85

[28] Ram, F. Wedzicha, J. Wright, J. and Greenstone, M. (2009). 'Hospital at home for exacerbations of chronic obstructive pulmonary disease (Review). The Cochrane Collaboration

[29] Scott,T. Mannion, R. Davies, H. and Marshall, N. (2003). 'Implementing culture change in health care: theory and practice'. International Journal for Quality in health Care,15(2),pp. 111-117.

[30] Sieloff, C. (2004). 'Leadership behaviours that foster nursing power'. Journal of Nursing Management. 12 pp: 246-251

[31] Skwarska, E. Cohen, G.Skwarski, K.Lamb, C.Bushell, D.Parker, S.MacNee, W. (2000). Randomised controlled trial of supported discharge with patients with exacerbations of chronic obstructive pulmonary disease. Thorax. 55: $907-912$

[32] Wells, W. (2009) 'Hospital care at home. Supporting independent and healthy lives.' Dr foster intelligence. [ONLINE]. Available at: http//www hospital-care-at-home co.uk. (Accessed: 1 July 2011)

[33] Zwarensatein, M. Goldman, J. and Reeves, S (2009). Interprofessional collaboration: effects of practice-based interventions on professional practice and healthcare outcomes. Cochrane Effective practice and Organisation of Care Group

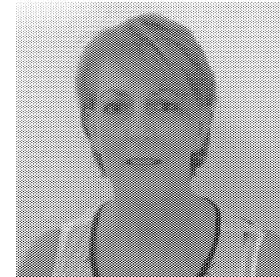

Sally

Hickman

completed her training in Chester in 1982 and subsequently worked in a variety of specialities. In 1992, she moved to

London and worked in Greenwich District Hospital on a respiratory ward. It was during this time that the interest and passion for respiratory nursing developed. She moved to Joyce Green Hospital as a Ward Sister, within 2 years moved to Chelsea and Westminster Hospital and took up the position of Respiratory Nurse Specialist. During the last ten years she has continued to study and has a BSc (Hons) in Respiratory Management and MA in Professional Practice. For the last ten years she has worked in Queen Elizabeth Hospital working collaboratively with her community colleagues.

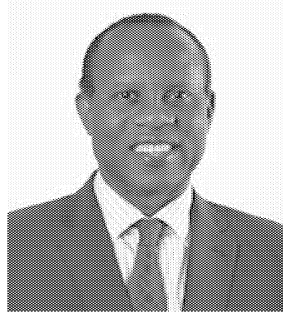

Dr Omorogieva Ojo has

$\mathrm{PhD}$ in Nutrition and PgDip in Diabetes. He is a Senior Lecturer in primary care in the Department of Acute and Continuing Care, University of Greenwich, London. His key interest and areas of expertise include nutrition, diabetes and other long term conditions which form the focus of his research and teaching activities.

Dr Ojo supervises both undergraduate and postgraduate research students and his publications and conference presentations are recognised both nationally and internationally. $\mathrm{He}$ has been a keynote speaker at the National Nurses Nutrition Group conference, a reviewer for Journals, Editorin-Chief of Nigerian Journal of Health Management and sits on the Editorial Board of American Journal of Food and Nutrition. 